DOI: 10.14451/1.174.70

\title{
СОЦИАЛЬНО ОТВЕТСТВЕННОЕ ВЕДЕНИЕ БИЗНЕСА В ЦЕПОЧКАХ ПОСТАВОК
}

\author{
(C) 2019 Тубелис Юлия Александровна \\ аспирант
}

Санкт-Петербургский государственный экономический университет, Россия, Санкт-Петербург

E-mail: tubelis.iuliia@gmail.com

В статье рассматриваются актуальность реализации концепции корпоративной социальной ответственности в цепочках поставок. Определена основная терминология, а также предложены принципы практической реализации концепции социальной ответственности цепочек поставок.

Ключевые слова: Корпоративная социальная ответственность, цепочки поставок, бизнес-процессы, управление цепочкой поставок, конкурентное преимущество

В эпоху глобализации и всё большей зависимости предпринимательства от международных рынков сырьевой продукции, оборудования, запасных частей, сопутствующих товаров и даже рабочей силы фирмам следует уделять особое внимание корпоративной социальной ответственности (КСО) и её составляющим: экологической и социальной ответственности. Сегодня многие компаний инициируют и внедряют практики, которые можно рассматривать как деятельность в соответствии с корпоративной социальной ответственностью.

Предприятия осознали важность заботы об окружающей среде, и стали рассматривать экологические проблемы как важную часть социальной ответственности. Когда речь идет об управлении цепочками поставок, важно изучить вопрос о том, все ли поставщики и другие компании в цепочке реализуют деятельность и практику КСО: все компании, включая поставщиков, берут на себя ответственность не наносить вред окружающей среде, сокращать загрязнения и отходы, контролировать выбросы газа и соблюдать нормативные акты, одновременно снижая стоимость производства и увеличивая его производительность.

Растущее беспокойство по поводу окружающей среды стимулирует правительства и международные организации, такие как Европейский Союз и Европейская комиссия, принимать новые законы и правила. Таким образом, все участники, в том числе поставщики и производители, в жизненном цикле продукта берут на себя экологическую ответственность.

Несмотря на то, что деятельность в области КСО требует больших инвестиций, компаниям важно интегрировать концепцию корпоратив- ной социальной ответственности в свои процессы для повышения удовлетворенности и лояльности клиентов, улучшения корпоративного имиджа, репутации, повышения производительности, снижения затрат и, следовательно, увеличение прибыли.

С каждым годом отношение потребителей к социальным и экологическим проблемам повышаются, что также является причиной для внедрения практик КСО. Исследования показали, что потребители предпочитают продукты компаний, которые придают значение защите окружающей среды и делают упор на работе с социальной ответственностью [7]. Полученные данные также показали, что репутация и позитивный имидж компаний перед обществом играют важную роль, что обеспечивает этим компаниям конкурентное преимущество.

Вне зависимости от области бизнеса для того, чтобы выдерживать и противостоять конкуренции, компаниям просто необходимо разрабатывать собственную стратегию КСО и планировать соответствующую деятельность.

Важную роль в логистической цепи играют поставщики. Большое количество поставщиков у крупных компаний может способствовать возникновению ощутимых рисков, связанных с качеством сырья, количеством бракованной продукции, а также с организацией производства [1].

Управление цепочками поставок - это организация, планирование, контроль и регулирование товарного потока начиная с получения заказа, закупки сырья и материалов для обеспечения производства товаров и далее через производство и распределение доведение его с оптимальными затратами ресурсов до конечного потребителя в соответствии с требованиями 
рынка [9]. Понятие «управление социальной ответственностью означает не только и не столько корпоративное управление с позиций КСО, а системный взгляд на комплекс взаимосвязей производителя с остальными участниками цепи поставок с целью удовлетворения потребностей общества [3].

С учетом этих процессов основными областями социальной ответственности в цепочках поставок являются [5]: организационные аспекты, этические аспекты, деятельность в отношении окружающей среды, деятельность в отношении прав человека и условий труда, охрана труда и техника безопасности, деятельность по установлению отношений с потребителями и обществом в целом.

Ниже рассмотрим примеры основных областей социальной ответственности в цепочках поставок.

1. Организационные аспекты:

- Определение целей КСО для процесса закупки,

- Определение ролей и обязанностей трудовых ресурсов, связанных с КСО в логистике,

- Обучение в области КСО для поставщиков,

- Обмен информацией и получение обратной связи в сфере КСО со всеми заинтересованными сторонами.

2. Этические аспекты:

- Не создавать незаконное давление на поставщиков,

- Не отдавать предпочтение какому-либо конкретному поставщику только из-за желания менеджера, а также стремиться обеспечить честный процесс отбора,

- Убедиться, что все подразделения совершают независимые закупки в соответствие с этическими стандартами,

- Не создавать незаконное конкурентное преимущество с помощью отдельных пунктов контракта.

3. Деятельность в отношении окружающей среды:

- Покупка и использование переработанных материалов для производства упаковки,

- Поддержка и поощрение поставщиков, сокращающих размер отходов (особенно это касается опасных отходов),

- Применение перерабатываемых материалов при производстве и дизайне продукта,

- Соответствие стандартам защиты окружающей среды в процессах управления жизнен- ным циклом продукта, его производства, упаковки и хранения,

- Поддержка поставщиков при внедрении процессов по защите окружающей среды.

4. Деятельность в отношении прав человека и условий труда:

- Обеспечение наличие процедур и механизмов контроля с целью предоставления равных прав и возможностей для каждого сотрудника, работающего во всех компаниях-поставщиках,

- Обеспечение наличия соответствующих нормативных процедур, для того, чтобы все сотрудники могли пользоваться своими законными правами, работали в соответствии с правилами, положениями и национальными / международными стандартами.

5. Охрана труда и техника безопасности:

- Обеспечение наличия соответствующих регулирующих процедур, при которых условия труда не ставят под угрозу здоровье и безопасность человека,

- Обеспечение принятия всех мер безопасности для различных видов деятельности,

- Обеспечение наличия процедур, контролирующих хранение особых видов продуктов в соответствующих условиях.

6. Деятельность по установлению отношений с потребителями и обществом в целом:

- Разработка и реализация программ по обучению и развитию местных поставщиков,

- Активное участие и организация некоммерческих общественных мероприятий, таких как работа волонтеров, благотворительные организации и т.п.,

- Обучение и поддержка спортивных мероприятий.

Среди вышеперечисленных видов деятельности именно соответствие всем региональным и международным правилам, положениям и стандартам, а также работа с поставщиками, которые отвечают одинаковым требованиям, представляют собой наиболее важные факторы для применения КСО в цепочках поставок. Реализация данного вопроса необходима с целью развития конкурентоспособности бизнеса на рынке и обеспечения стабильного роста с точки зрения стратегической перспективы.

За последнее десятилетие вопросы экологии остаются одними из популярных направлений в области КСО. Отчасти этому способствовало то, что Всемирный экономический форум 2009 г. 
провозгласил курс на «зеленую» экономику, уменьшение экологических угроз и рисков [2].

Принципы компании по отношению к проблемам окружающей среды в различных процессах цепочек поставок могут быть объединены в понятии «зеленое» управление цепочками поставок (УЦП).

Зачастую компании воспринимают практики «зеленого» УЦП как факторы, увеличивающие стоимость конечного продукта. Исследования показали, что практика «зеленого» УЦП помогает компаниям снизить общие затраты, повысить производительность, стимулировать инновации, экономить ресурсы и повышать конкурентные преимущества [10]. Помимо этих ощутимых преимуществ, практика «зеленого» управления цепочками поставок также играет важную роль в повышении удовлетворенности работой сотрудников и их приверженности компании, лояльности клиентов, повышения репутации компании в глазах общества.

Основная цель «зеленого» управления цепочками поставок - гарантировать, что меры по охране окружающей среды применяются на всех этапах процесса: закупка, производство, упаковка, складирование, распределение и сборка. Долгосрочная цель «зеленого» УЦП состоит в том, чтобы держать под контролем все процессы, сократить химические отходы, уменьшить выбросы газа и устранить те виды деятельности, которые могут быть опасными для окружающей среды.

Компании могут иметь разные подходы при реализации «зеленого» управления цепочками поставок. Начиная от минимального внедрения практик, которые соответствуют действующим нормам и правилам, например, практику соблюдения прав человека, минимальное использование ресурсов, поставку переработанных продуктов и до систематического интегрирования своей экологической политики в собственные долгосрочные бизнес-стратегии, которые отражают эту политику в принимаемых решениях. Так же, эти компании устанавливают тесную связь со своими поставщиками и заинтересованными сторонами и поощряют их интегрирование экологической политики в их бизнес-процессы.

Другие важные задачи концепции «зеленого» управления цепочками поставок включают выбор критериев и показателей экологической эффективности для дальнейшего изучения её взаимосвязи с производительностью. Чтобы измерить достижения интеграции «зеленого» УЦП, компании определяют факторы успеха в соответствии с их областями деятельности [4]. Определение и измерение этих факторов помогают компаниям понять эффективность экологической политики и указать, насколько хорошо эта политика интегрирована в бизнес-процессы. Ниже приведены некоторые факторы успеха, которые могут быть использованы для измерения эффективности экологической политики:

- Количество отходов, подвергших негативному воздействию окружающую среду,

- Количество опасных материалов, используемых в процессе производства,

- Объем использования топлива и выбросов газа при производстве, хранении и транспортировке,

- Количество партнерских отношений с поставщиками, заботящимися об окружающей среде,

- Уровень репутации компании с точки зрения природоохранной деятельности в глазах общественности.

Компании, интегрирующие практику «зеленого» управления цепочками поставок, могут оценивать эффективность своей деятельности и процессов с точки зрения экологических проблем и при необходимости корректировать свои планы и стратегии.

Социально ответственные практики и методы должны применяться на всех уровнях и этапах процесса цепочки поставок, от закупки сырья до доставки продукции покупателю. Ниже рассмотрим примеры социально ответственных практик на каждом из этапов.

Социальная ответственность в сфере закупок может быть определена как выполнение всех закупочных действий в соответствии с принципами КСО и с учетом данных принципов в процессе принятия решений [6]. Если компания соблюдает соответствующие стандарты по экологическим вопросам и использует отработанные социально ответственные практики в процессах, то это может стать важным шагом на пути распространения концепции КСО среди поставщиков. Одними из практик КСО, которые могут быть интегрированы в сферу закупок, являются предпочтение переработанным и/или перерабатываемым материалам, закупка сырья, пригодного для вторичной переработки, выбор технологий, потребляющих меньше энергии и 
производящих меньше отходов [12].

Кроме того, выбор правильных поставщиков, которые также применяют концепции КСО в собственных процессах и соблюдают соответствующие правила и положения, играет важную роль в части закупок с точки зрения будущих перспектив. В этом отношении, прежде чем начинать закупки с поставщиками, компании необходимо убедиться, что поставщики также внедряют необходимые принципы КСО в своих процессах.

Социальная ответственность в производственном процессе может заключаться во внедрении систематического механизма сокращения количества отходов и их утилизация без какой-либо опасности для природы. Еще одна важная цель КСО в производстве - оценка каждой фазы жизненного цикла продукта для определения возможностей повторного производства и использования материалов, участвующих в самом производственном процессе. Если подобная возможность существует, то следует интегрировать её на благо общества [4].

Социальная ответственность в перевозке и распространении продукта требует развития необходимых транспортных и распределительных возможностей для поддержания и повышении экологической, экономической и социальной устойчивости [5]. Социально-ответственные практики в области транспортировки включают предоставление возможностей местным транспортным компаниям, тщательный контроль за соблюдением правил дорожного движения, внедрение механизмов, повышающих безопасность и надежность при транспортировке.

За последние годы на компании оказывается заметное давление с целью уменьшения негативного воздействия упаковочного материала на окружающую среду. Законы и нормативные акты, принятые в последнее время, увеличивают важность КСО на этапе упаковки. В последнее время влияние упаковочного процесса на окружающую среду рассматривается в рамках жизненного цикла продукта. В соответствии с концепцией КСО в процессе упаковки необходимо рассмотреть несколько действий: хранение, складирование, защита продукта от порчи. На протяжении всех этих процессов принципы корпоративной социальной ответственности требуют использования переработанного и безопасного материала, сокращения отходов, сокращения потребления энергии и разработки всего процесса таким образом, чтобы не наносить вреда экосистеме [6]. Размер упаковки так же стал важным фактором, так как он напрямую определяет количество используемого материала. Кроме того, небольшой размер упаковки помогает компаниям наиболее оптимально определить свои нагрузки и снизить транспортные расходы.

Социальная ответственность в области хранения товара начинается с выбора местоположения складов с учетом всех соответствующих экологических и социальных факторов. Обеспечение правильного и безопасного хранения продукции, производство избыточного количества товаров на благо общества также рассматриваются в рамках концепции КСО. Принятие мер предосторожности для обеспечения здоровья и безопасности работников на складах также является важным аспектом деятельности [5].

Управление обратной цепочкой поставок это последовательность действий или процесс по извлечению использованного продукта у потребителя и его дальнейшей утилизации или повторного использования. Данная концепция также применяется на этапах транспортировки, хранения, управления запасами и сотрудничества с партнерами [8]. И хотя внедрение и контроль обратных цепочек поставок требуют значительных инвестиций, они приносят экономические и конкурентные преимущества, а также стратегическое значение для компаний, которые их интегрируют в собственное производство. Прежде всего, компании, внедряющие обратные цепочки поставок, могут снизить свои затраты, сократив количество сырья и перепродавая продукты после утилизации [11]. Обратная цепочка поставок помогает компании создать «зеленый» имидж, укрепить свою репутацию в обществе и дает возможность построить более прочные отношения с потребителями. Обратное управление цепочками поставок представляет собой целостный и комплексный подход к управлению отходами и сокращению количества опасных материалов. Данный процесс довольно эффективен и адаптируется многими компаниями.

Под сильным влиянием растущей конкуренции, глобализации, коммуникационных и информационных технологий компании, пытающиеся сохранить свои позиции на рынке и поддержать устойчивый рост, все больше склоняются к применению действий и практик кор- 
поративной социальной ответственности.

Компании, успешно адаптирующиеся к социальным и экологическим практикам, могут добиться экономических выгод за счет сокращения затрат, повышения производительности и прибыли, улучшения имиджа и репутации компании. Однако, чтобы цепочки поставок были успешными с точки зрения КСО, организациям, включая всех поставщиков и производителей в цепочке, необходимо повышать свою осведомленность и действовать социально и экологически ответственным образом. Более того, они обязаны соблюдать экологические законы и правила, соответствовать национальным и международным стандартам и интегрировать практику корпоративной социальной ответственности в свои бизнес-процессы.

Улучшение репутации компании перед общественностью является отражением успешного применения практик КСО в цепочках поставок. Интеграция социальной ответственности в бизнес-стратегии может помочь также в укреплении взаимоотношений с потребителями.

\section{Библиографический список}

1. Готфрид А. Социально ответственное ведение бизнеса как важный критерий выбора поставщика // Молодой ученый. - 2016. - № 27.- С. 384-386.

2. Капустина Л. «Зеленые» технологии в логистической деятельности // Известия Уральского государственного экономического университета. - 2016. - № . 2 (64). - С.114-122.

3. Негомедзянов Ю., Негомедзянов Г. Управление социальной ответственностью цепей поставок// Проблемы теории и практики управления. - 2015 - № 7.- С. 87-92.

4. Büyüközkan, G., Vardaloğlu, Z. Yeşil Tedarik Zinciri Yönetimi// Lojistik Dergisi. - 2008. - № 8. - P.66-73.

5. Ciliberti F., Pontrandolfo P., Scozzi B. Logistics Social Responsibility: Standart Adoption and Practices in Italian Companies// International Journal of Production Economics. - 2008. - № 113. - P.88-106.

6. James K., Fitzpatrick L., Lewis H., Sonneveld K. Sustainable Packaging System Development// Handbook of Sustainability Research, Frankfurt, Germany: Peter Lang Scientific Publishing.- 2005.

7. Maignan I., Hillebrand B., McAlister D. Managing Socially Responsible Buying: How to Integrate Non-Economic Criteria into Purchasing Process// European Management Journal. - 2002. - № 20(6). - P.641-648.

8. Prahinski C., Kocabaşoğlu C. Empirical Research Opportunities in Reverse Supply Chain// the International Journal of Management Science. - 2006. - № 34.- P.519-532.

9. Standards. ELA Certification for Logistics Professionals: Glossary of Terms Used in Standards of Competence// Brussels: ELA/ECBL. - 2004.- P.15.

10. Van Hoek R. From Reversed Logistics to Green Supply Chains. Supply Chain Management// 1999. - № 4(3).P.129-134.

11. Wei Y. Reverse Supply Chain Management. Masters Thesis// University of Gothenburg. - 2011.

12. Zhu Q., Sarkis J., Lai K. Initiatives and Outcomes of Green Supply Chain Management Implementation by Chinese Manufacturers// Journal of Environmental Management._ 2007. - № 85.- P.179-189. 